\title{
Patients with extensive esthetic enhancement requests. Some tips for finishing and detailing
}

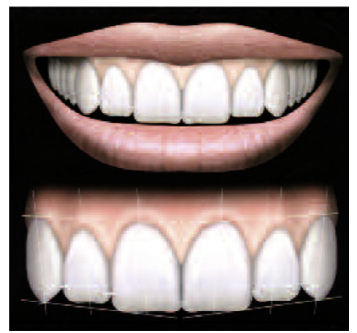

\section{Catherine GALLETTI}

\section{SUMMARY}

Faced with a patient who has extensive esthetic enhancement demands, simply aligning the teeth and achieving a functional occlusion might not suffice.

The goal of this article is to help orthodontists to analyze and to optimize the positioning of upper anterior teeth so as to improve the esthetics of the smile.

Of course, esthetics is not an objective notion. Therefore, maintaining good communication with our patients is essential. Nonetheless, esthetic rules as they are defined in the literature will serve as a "framework" for creating a smile.

In this context, the orthodontist will have to take into account the shape of the teeth, particularly since not all shapes are ideal. In fact, the incisors have three main shapes: rectangular, triangular and ovoid. The shape of the teeth will perhaps guide orthodontists in their choice of treatment. Opting for stripping will be the preferred treatment in some cases.

Similarly, orthodontists have to take into consideration incisal edge defects caused by wear associated with the initial malocclusion that becomes more apparent after alignment. In some cases, a simple recontouring or enameloplasty of the incisal edges will be sufficient and should be discussed with the patient before it is performed using a simple and reliable procedure.

\section{KEY WORDS}

Screening,

Periodontal disease,

Multi-disciplinary,

Probing measurement. 


\section{1 - INTRODUCTION}

The esthetic expectations of our patients, especially with adults, are varied and have changed considerably. Although some of them are satisfied with some minor esthetic enhancement, other patient can have a "long list" of esthetic requests.

They are not always satisfied with a simple alignment of the teeth and a functional occlusion.

In fact, most of these adult patients arrive with yellow teeth that

\section{2 - THE RULES OF ESTHETICS}

We are very aware that even the notion of a harmonious smile is a vast topic that cannot be summed up with a few simple rules of esthetics about the positioning of the teeth given its subjective nature and how it varies with the individual, the various cultures and even the sex of the person involved ${ }^{5,7}$. Of course, communication is the essential key if we are to fully understand the expectations of our patients.

However, these rules are very useful and can serve as a framework for constructing many smiles using prosthetic devices as described in numerous sources ${ }^{2,8}$. In orthodontics, we can also draw inspiration from these rules of esthetics.

The rules of esthetics that are described in the literature and used today in esthetic dentistry strongly are more or less damaged (Fig. 1). If a whitening procedure is possible in most cases, an alignment brings out defects due to wear sometimes related to the initial malocclusion (Fig. 2). In these situations, an enameloplasty or an esthetic recontouring of the incisal edges could be an excellent option for creating the optimal smile.

emphasize the notion of symmetry and the dominance of the central incisors. Mauro Fradeani ${ }^{2}$, among others, speaks of the radiant symmetry where the vertical position of the anterior teeth and their slight mesial inclination creates a harmonious effect on their contact points and their interincisal angles (Fig. 3).

In orthodontics, most of time we work on natural teeth. In 2004, Sarver" suggested that we "recontour the edges" and therefore the shape of the anteriors so that orthodontists might better "adhere" to the established rules of "esthetic dentistry".

We do not want to standardize the creation of the smile as "American orthodontists" do; however, sometimes recontouring the edges is useful for harmonizing the smile. 


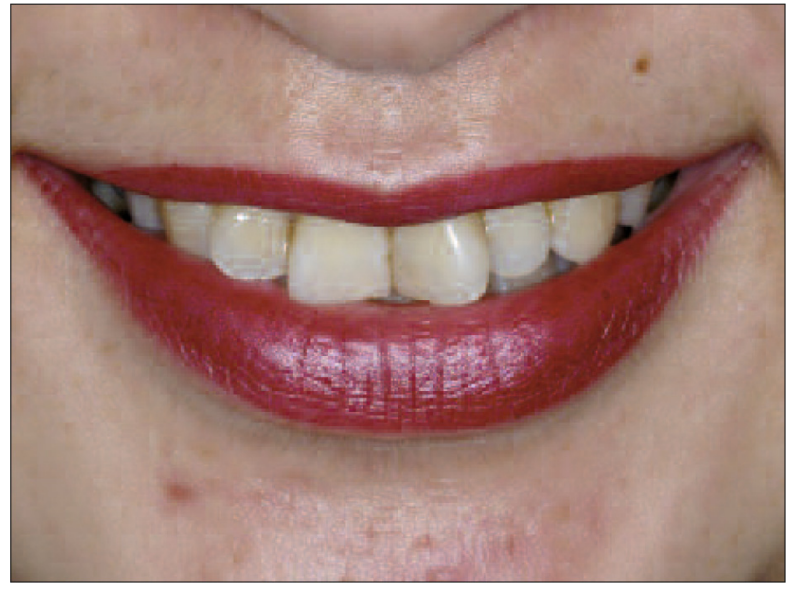

Figure 1

Smile of an adult before treatment. The teeth appear yellow and their edges are more or less damaged.

\section{3 - THE SHAPE OF THE TEETH}

The shape of the teeth is a very important notion and we have to be cognizant of all the implications of their form and contour on the esthetic result of treatment.

As Fradeani ${ }^{2}$ has stated, the incisors have three main shapes: rectangular, triangular and ovoid (Fig. 4)

The respective sides that are more or less straight, divergent or curved will determine the position and the extent of the points of contact between the opposing anterior teeth.

The harmonious alignment of rectangular incisors is easily created (Figs. 5 to 8) and has a positive impact on areas of contact of the adjacent teeth and their intercisal angles.

Whereas in the initial situation of crowding, the divergence of the dis-

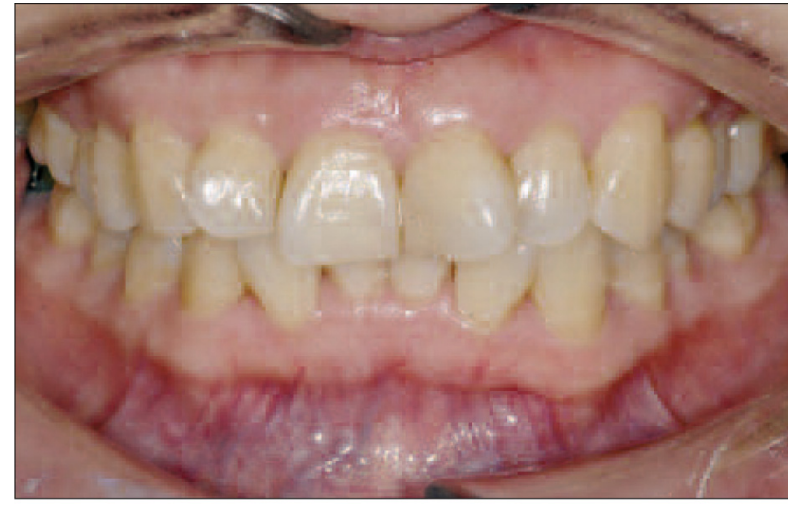

a

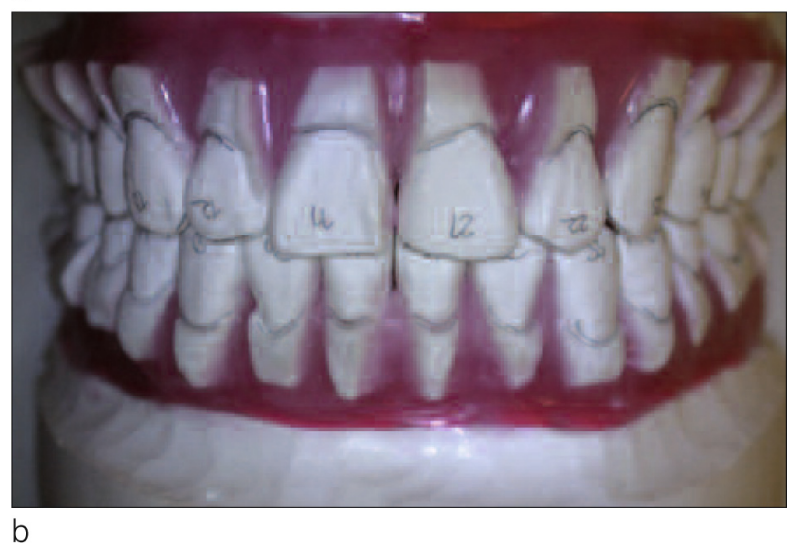

Figures $2 a$ and $2 b$

Front intraoral view before treatment (a) and after alignment on the set-up (b) that shows the defects. (wear sometimes associated with the initial malocclusion).

tal edges of triangular incisors will more incisally position the contact point after alignment.

This situation for an adult patient is the cause of the appearance of unsightly black triangles on the gingival papillae that have not changed in volume during treatment. That is why some authors recommend that we use "stripping" in order reduce these triangles associated with the gingiva so that these wide spaces disappear $^{1,6}$ (Figs. 9a to 9c). 


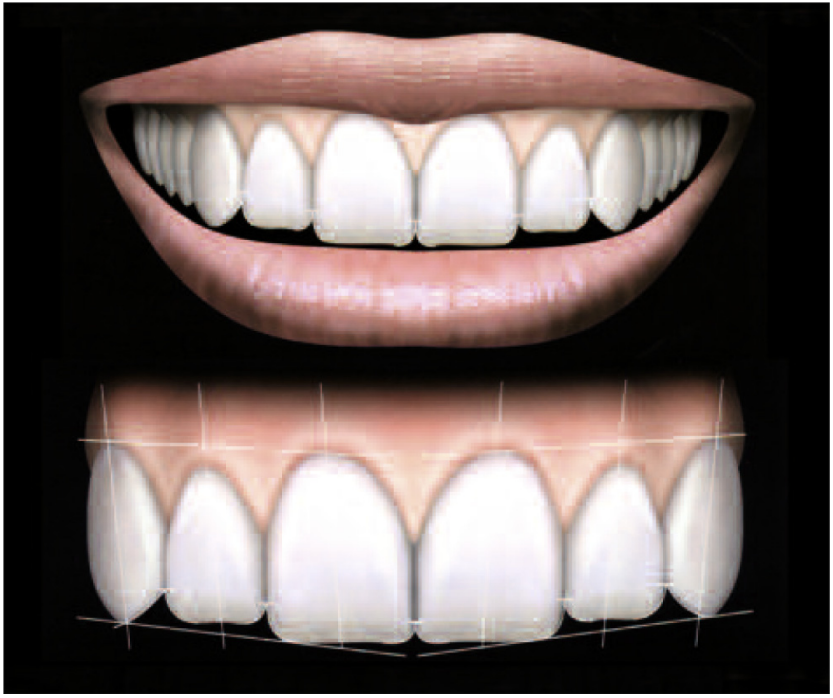

Figure 3

Diagrams show the rules of esthetics for the smile as they appear in M. Fradeani's ${ }^{2}$ book.

Stripping or reducing mesio-distal enamel can be, in this case, an alternative to dental extraction in cases of minor or moderate crowding.

Various studies have been published on this subject indicating that stripping was not accompanied by caries or periodontal disease ${ }^{4,9-12}$ if no more than $50 \%$ of enamel is removed. It is recommended that the orthodontist perform an "anatomical" stripping followed by a meticulous polishing.

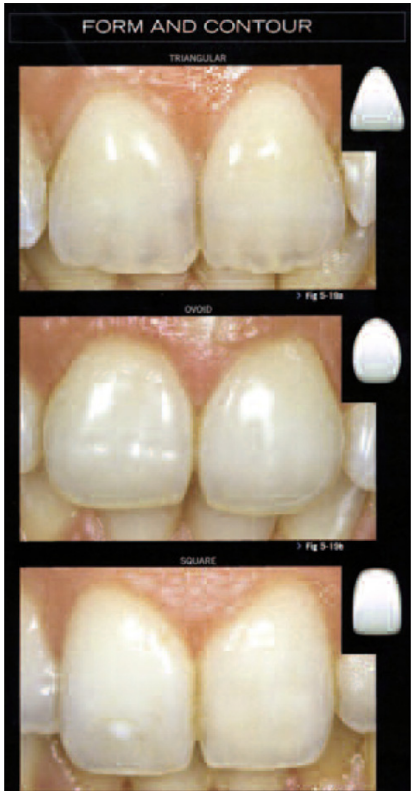

Figure 4

The three main shapes of the maxillary incisors (according to Fradeani ${ }^{2}$ ).

Ovoid-shaped teeth are the most difficult to esthetically align. The peripheral curves that are more or less pronounced, will, in this case, position the point of contact in the gingival direction. Some teeth may look worse after alignment after alignment and some patients will not like them. The orthodontist can solve this problem by compensating and creating "the best" mesio-distal inclination that may involve stripping in order to soften the peripheral curves (Figs. 10 and 11).

\section{4 - ENAMELOPLASTY OR RECONTOURING}

Esthetic recontouring of the incisal edges will be a more subtle approach. On the other hand, studies that have been done on esthetic pre- ferences within populations have shown that rounding the incisal angles is requested since it is a sign of femininity and glamor ${ }^{3}$. As we have 


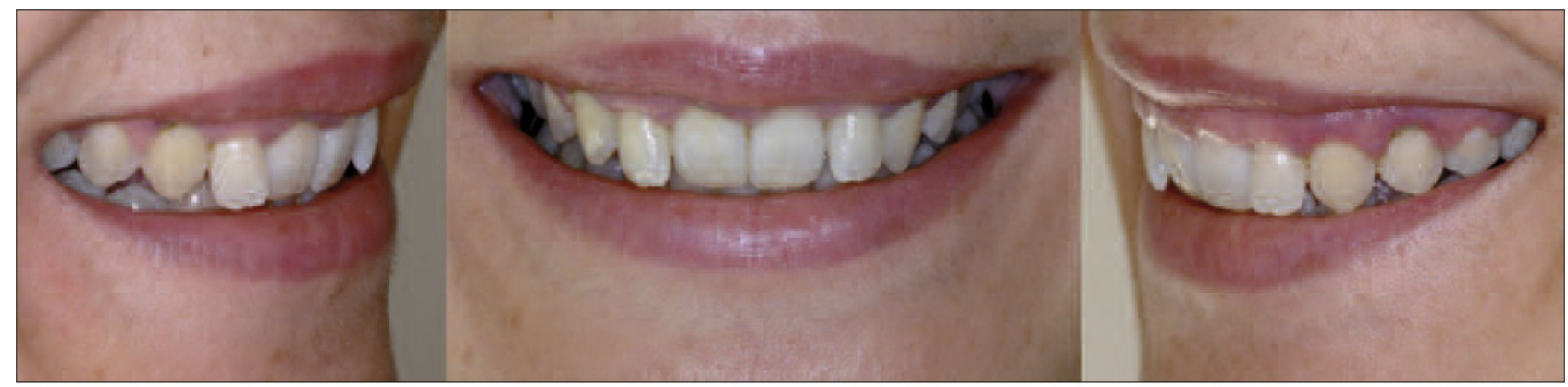

a

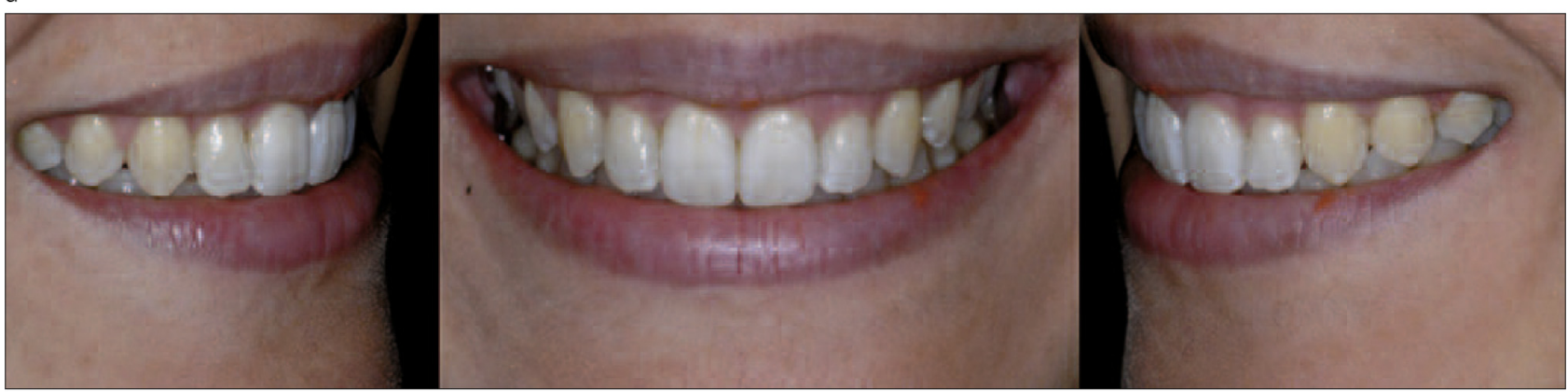

b

Figures $5 a$ and $5 b$

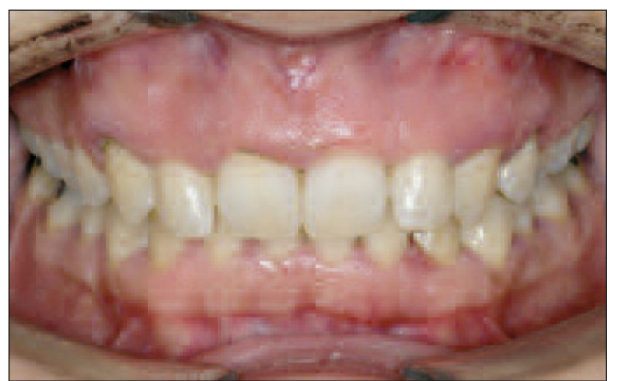

a

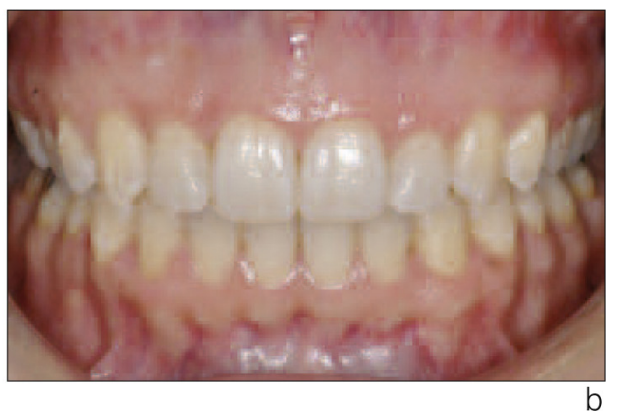

$\mathrm{b}$

Figures $6 a$ and $6 b$

already stated, there is a great deal of subjectivity involved. Our patients are hesitant because it is an irreversible procedure. Therefore, the orthodontist really needs a simpler and more effective procedure that reassures the patient and that also makes the practitioner feel confident about the end result while performing it.
We are proposing the use of a technique called previsualization that requires an open discussion between the patient and the practitioner.

\section{4 - 1 Previsualization}

The orthodontist uses a black marker in order to blacken the wide 

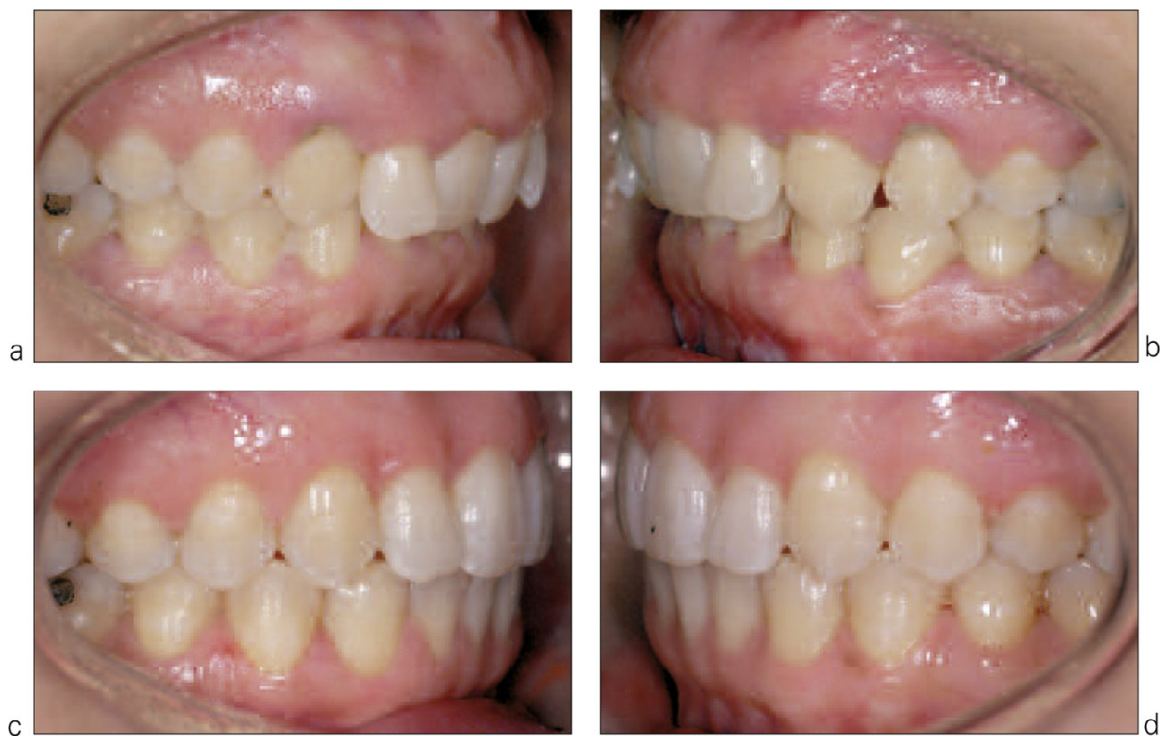

Figures 7a to $7 d$
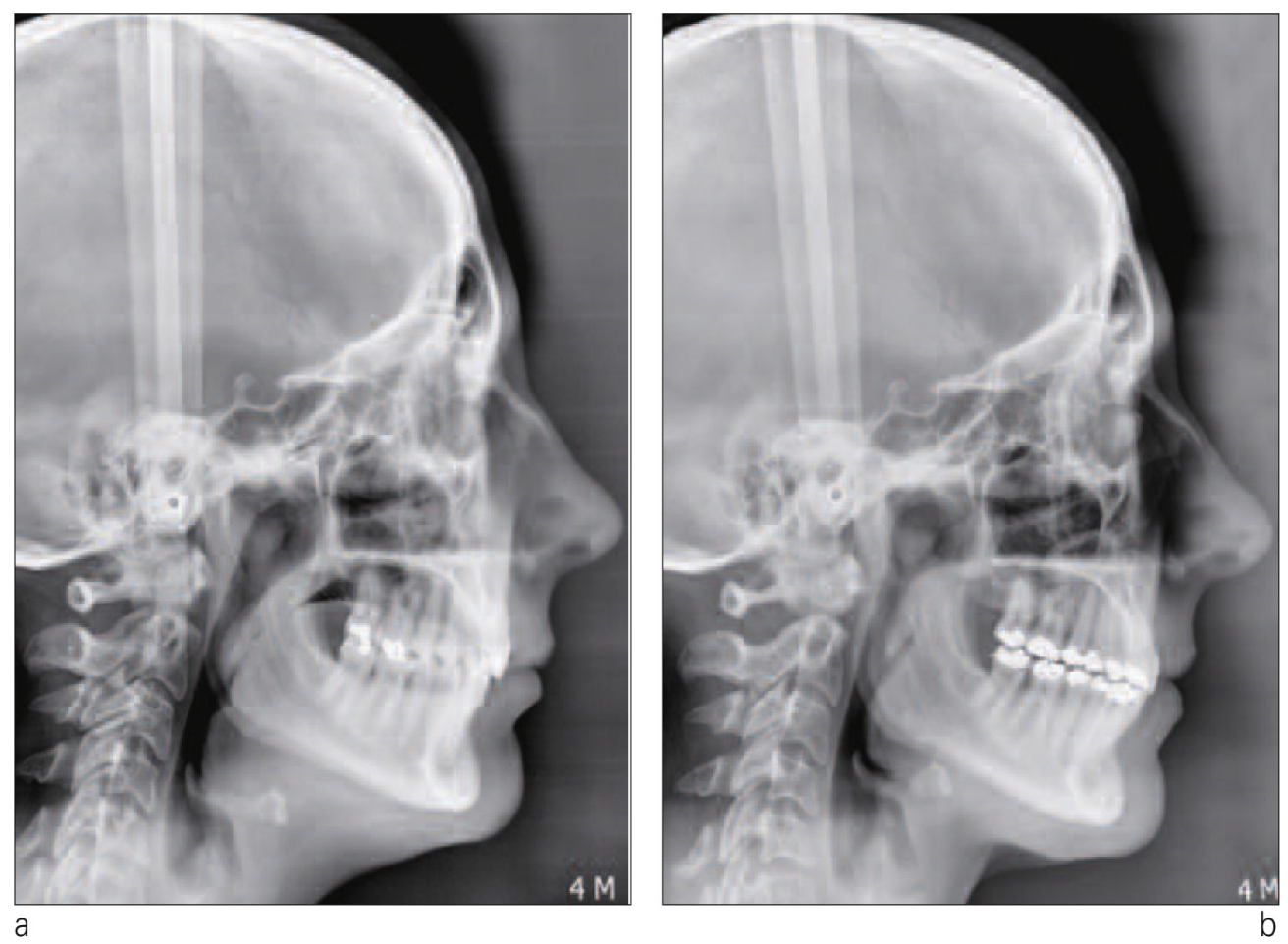

Figures $8 a$ and $8 b$

Figures 5 to 8

The smile of an adult patient before (Fig. 5a) and after treatment (Fig. 5b) presenting rectangular-shaped upper incisors. Achieving a harmonious smile takes place after decompensating the malocclusion and performing a gingivoplasty or crown lengthening. 


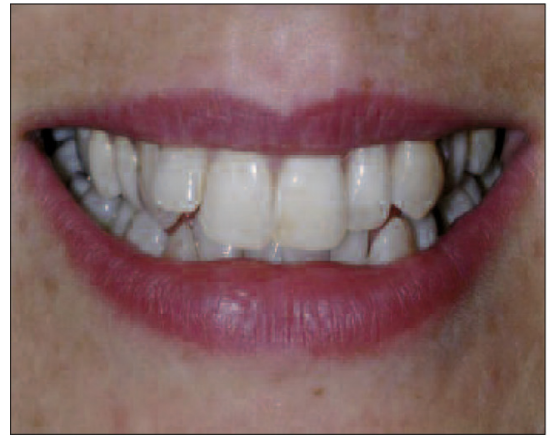

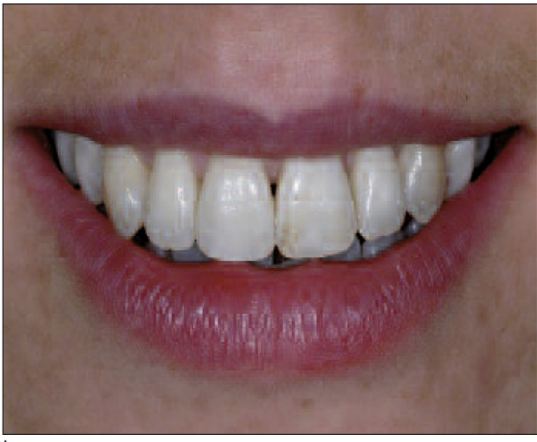

b

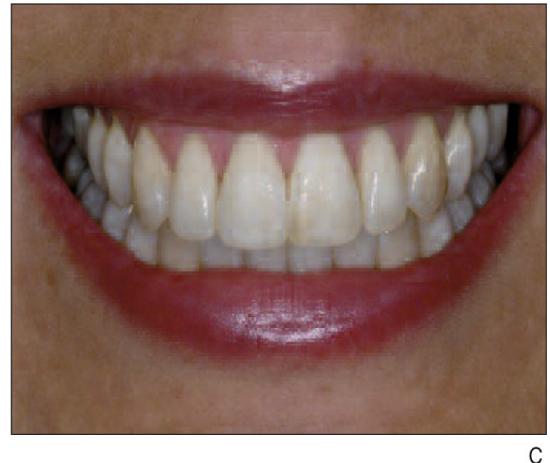

Figures 9a to 9c

The triangular-shaped teeth are prone to the appearance of dark triangles near the papillae. The divergence of the distal edges will in fact position the point of contact near the incisal edge after alignment. Stripping is recommended in this case.

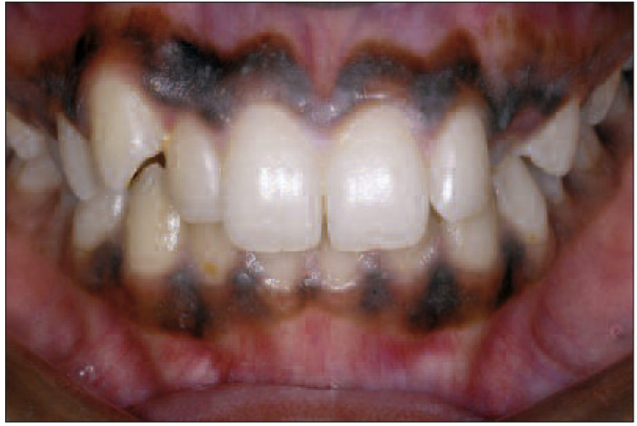

a

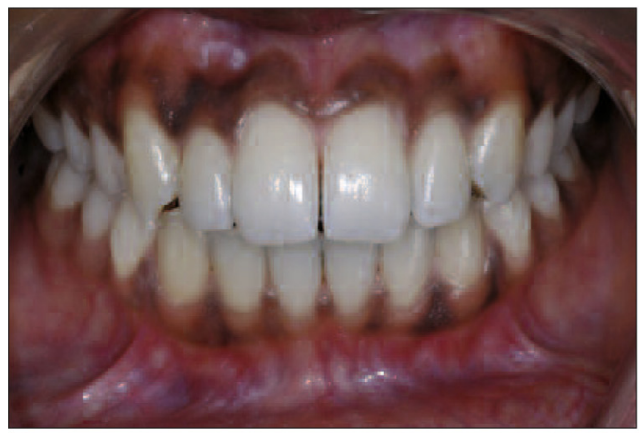

C
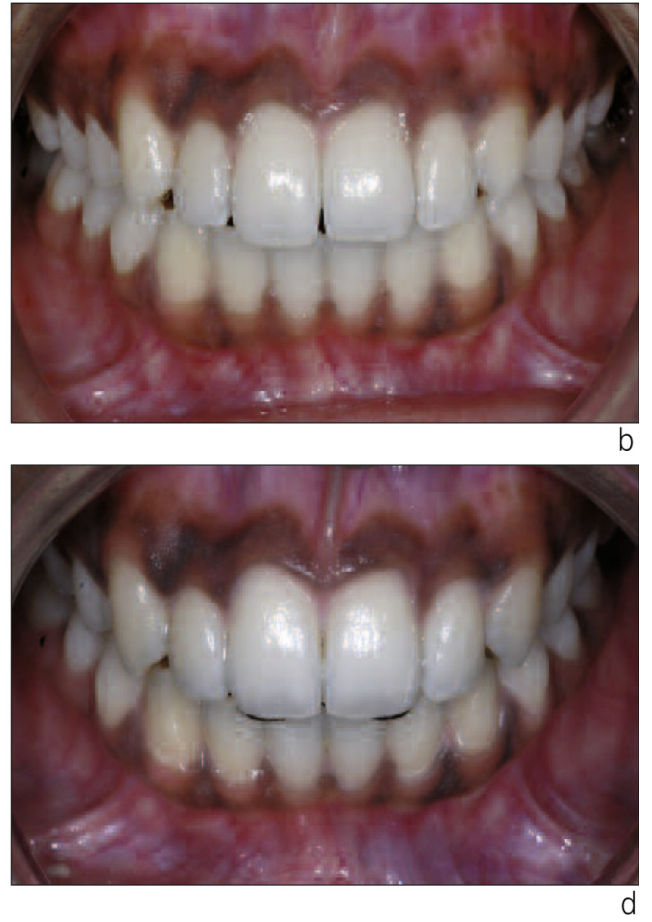

Figures 10a to 10d

The ovoid-shaped teeth will position the contact point in a gingival direction. The "best" mesio-distal inclination is the objective here. To obtain a more harmonious smile, the orthodontist will do a light stripping in order to soften the peripheral curves and to harmonize the contacting intercisal angles. 


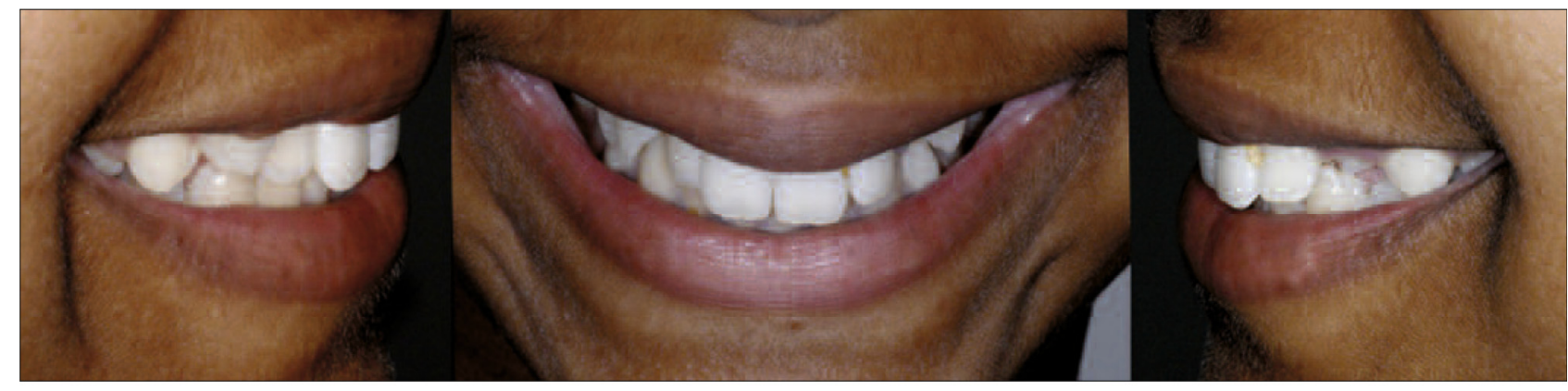

a

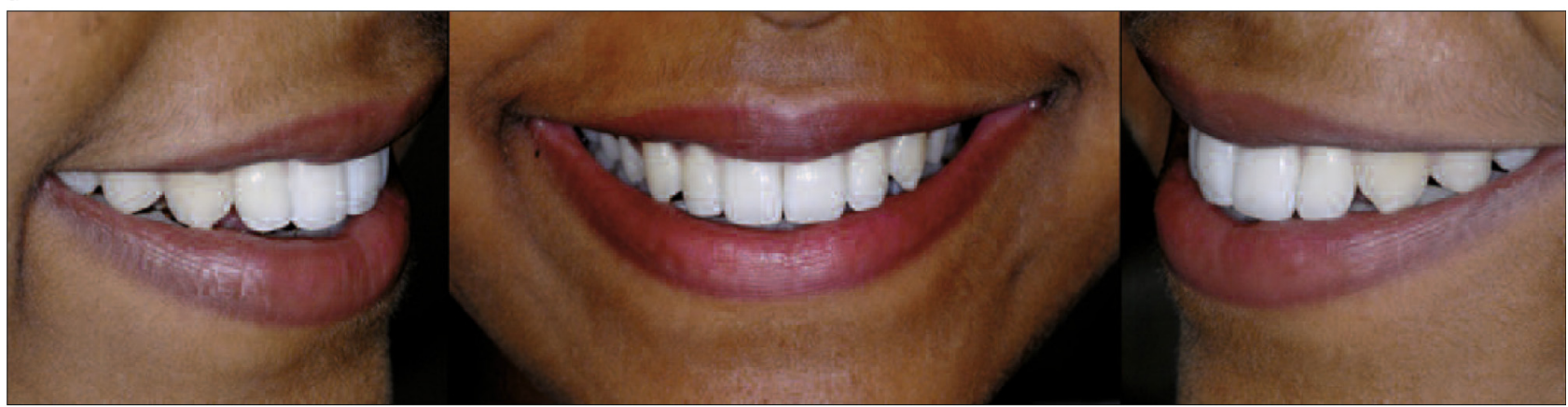

b

Figures $11 a$ and $11 b$

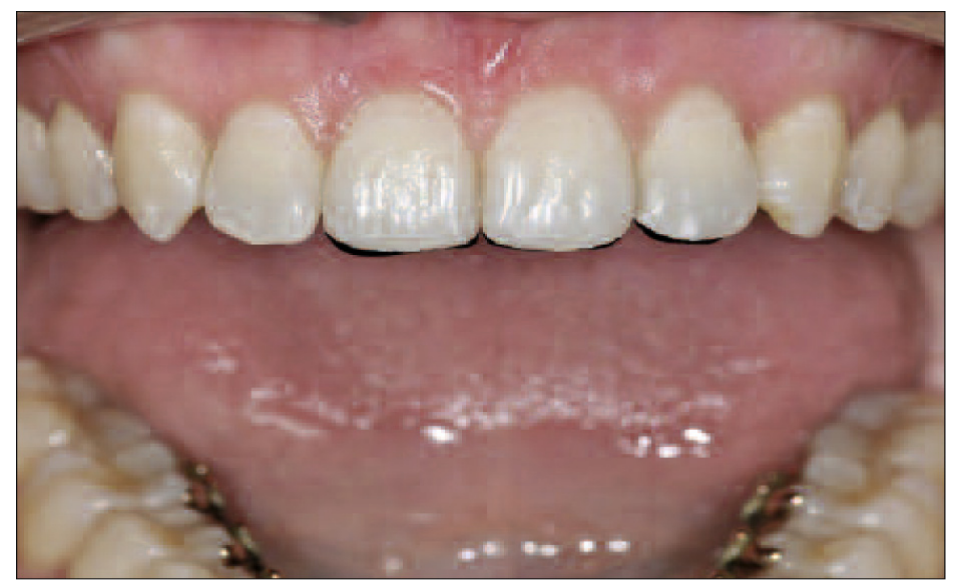

Figure 12

A black marker is used in order to previsualize the proposed recontouring. 


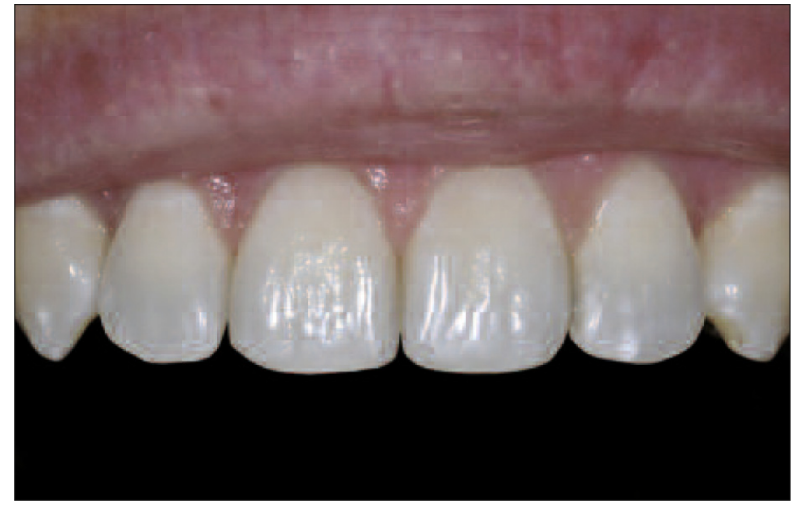

Figure 13

For patients, the blackened marks blend in with the shadow inside the mouth as they slightly open it and look at themselves in the mirror.

areas of the incisal edges that need to be retouched (Fig. 12).

Previsualization is done for patients by using a mirror as they slightly open the mouth so that the blackened areas blend in with the shadow inside the mouth (Fig. 13).

\section{4 - 2 The validation process}

There are three possible situations here. The patient agrees and the practitioner only has to retouch the

\section{CONCLUSION}

Improving the smile of patients who have extensive esthetic requests can push the limits of orthodontics.

However, we must keep in mind that some situations will be difficult

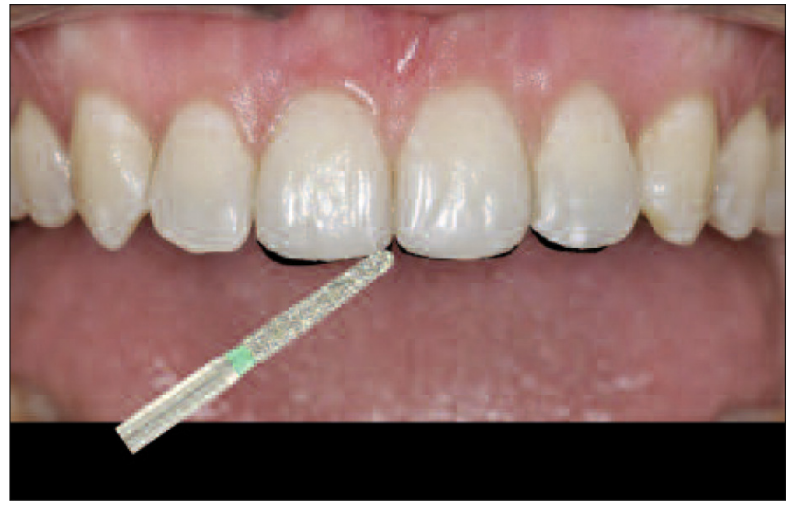

Figure 14

After a recontoured line is agreed upon, the practitioner only has to proceed with the recontouring by using a straight diamond drill and following the blackened marks.

edges by following the previously placed marks. Visually, if the marks are not ideally what the patient wants, then they have to be adjusted or the procedure is abandoned.

\section{4 - 3 The procedure}

The recontouring is performed by using a straight diamond drill mounted on a turbine (Fig. 14).

This will be followed by a light polishing with a fine grain strip band.

to manage without some of the techniques of esthetic dentistry.

An open discussion with the patient is a crucial component of treatment in order to avoid any misunderstanding. 


\section{REFERENCES}

1. Chow YC, Eber RM, Tsao YP, Shotwell JL, Wang HL. Factors associated with the appearance of gingival papillae. J Clin Periodontol 2010;37(8):719-27.

2. Fradeani M. Esthetic analysis: a systematic approach to prosthetic treatment. In: Esthetic rehabilitation in fixed prosthodontics. Vol. 1. Chicago: Quintessence Publishing Co, Inc., 2004.

3. Heravi F, Rashed R, Abachizadeh $\mathrm{H}$. Esthetic preferences of the shape of anterior teeth in a posed smile. Am J Orthod Dentofacial Orthop 2011;139(6):806-14.

4. Jarjoura K, Gagnon G, Nieberg L. Caries risk after interproximal enamel reduction. Am J Orthod Dentofacial Orthop 2006;130(1):26-30.

5. Kokich VO, Kokich VG, Kiyak HA. Perceptions of dental professionals and laypersons to altered dental esthetics: asymmetric and symmetric situations. Am J Orthod Dentofacial Orthop 2006;130(2): 141-51.

6. Kurth JR, Kokich VG. Open gingival embrasures after orthodontic treatment in adults: prevalence and etiology. Am J Orthod Dentofacial Orthop 2001;120(2):116-23.

7. McLeod C, Fields HW, Hechter F, Wiltshire W, Rody W, Christensen J. Esthetics and smile characteristics evaluated by laypersons. Angle Orthod 2011;81(2):198-205.

8. Sarver DM. Principles of cosmetic dentistry in orthodontics: Part 1. Shape and proportionality of anterior teeth. Am J Orthod Dentofacial Orthop 2004;126(6):749-53.

9. Thordarson A, Zachrisson BU, Mjör IA. Remodeling of canines to the shape of lateral incisors by grinding: a long-term clinical and radiographic evaluation. Am J Orthod Dentofacial Orthop 1991; 100(2):123-32.

10. Zachrisson BU. Actual damage to teeth and periodontal tissues with mesiodistal enamel reduction («stripping»). World J Orthod 2004;5(2):178-83.

11. Zachrisson BU, Nyøygaard L, Mobarak K. Dental health assessed more than 10 years after interproximal enamel reduction of mandibular anterior teeth. Am J Orthod Dentofacial Orthop 2007; 131(2):162-9.

12. Zachrisson BU, Minster L, Øgaard B, Birkhed D. Dental health assessed after interproximal enamel reduction: caries risk in posterior teeth. Am J Orthod Dentofacial Orthop 2011;139(1):90-8. 